

\title{
$A B C B 1$ gene expression in peripheral blood mononuclear cells in healthy Thai males and females
}

\author{
P. Sudchada, S. Oo-puthinan, O. Kerdpin and N. Saelim \\ Department of Pharmacy Practice, Faculty of Pharmaceutical Sciences, \\ Naresuan University, Phitsanulok, Thailand \\ Corresponding author: P. Sudchada \\ E-mail: patcharaporns2000@yahoo.com
}

Genet. Mol. Res. 9 (2): 1177-1185 (2010)

Received February 24, 2010

Accepted March 22, 2010

Published June 22, 2010

DOI 10.4238/vol9-2gmr813

\begin{abstract}
We compared the expression of the $A B C B 1$ gene in healthy male and female Thai subjects; this gene encodes the P-glycoprotein transporter in peripheral blood mononuclear cells (PBMCs). We also identified the most suitable housekeeping genes for normalization of $A B C B 1$ expression levels in PBMCs. PBMCs from 30 females and 26 males were isolated. Total RNA was extracted, followed by reverse transcription (100 ng total RNA per sample). The internal normalization controls were actin- $\beta, \beta-2 M$ and GAPDH. Real-time quantitative PCR was then performed to determine the expression levels of the $A B C B 1$ gene. The expression levels were found to be 1.5- to 2.5-fold higher in males, depending on the endogenous control used for normalization. Actin- $\beta$ was the most stable control gene and could be used as a single endogenous control for normalization of $A B C B 1$ expression levels in PBMCs. However, more than one endogenous control genes are recommended for normalization of gene expression. We conclude that the expression levels of $A B C B 1$ in PBMCs is influenced by gender; this helps, in part, explain the gender difference in pharmacokinetics and
\end{abstract}


pharmacodynamics of drugs that are P-glycoprotein substrates. $A B C B 1$ gene expression profiles need to be carefully interpreted with regards to the endogenous control genes that are involved.

Key words: Gender difference; $A B C B 1$ expression; Peripheral blood mononuclear cells

\section{INTRODUCTION}

Among the human ATP binding cassette $(\mathrm{ABC})$ transporters, multi-drug resistance protein $1(A B C B 1 ; M D R 1)$ gene, which encodes $\mathrm{P}$-glycoprotein $(\mathrm{P}$-gp) is the most extensively studied transporter (Schinkel and Jonker, 2003; Hoffmann and Kroemer, 2004). The differences in $\mathrm{ABC}$ transporter expression and functions are suggested to be the cause of inter-individual differences in susceptibility to differences in drug responses and pharmacokinetic properties including oral bioavailability and hepatobiliary, direct intestinal, and urinary excretion of drugs and drug-metabolites (Schinkel and Jonker, 2003; Hoffmann and Kroemer, 2004).

P-glycoprotein was first identified in human tumor cells, where it was found to be associated with pleiotropic multidrug resistance to cancer chemotherapeutic agents (Roninson et al., 1986). Normally, this efflux transporter is apically expressed in tissues including kidney, liver and intestine and the capillary endothelial cells of the blood-brain barrier, and it is found in various leukocyte lineages as well (Schinkel and Jonker, 2003; Hoffmann and Kroemer, 2004). The expression of $A B C B 1$ in peripheral blood mononuclear cells (PBMCs) is found to be crucial in the progression of diseases and drug deposition, where particularly the PBMCs are the target sites.

Gender difference in hepatic P-gp expression has been reported, with 2-fold lower expression found in females compared to males, possibly from the influence of sex hormones or growth hormones on $A B C B 1$ gene regulation (Schuetz et al., 1995; Potter et al., 2004). On the other hand, some reports showed no gender difference in intestinal P-gp (Paine et al., 2005; MacLean et al., 2008). Since P-gp is expressed at different levels in various tissues, the gender difference in protein expression found in intestine may not be similar to that in PBMCs. Recently, it was found that P-gp expression in intestine and liver does not correlate with its expression in PBMCs (Albermann et al., 2005). A study reported that males have greater expression levels of $A B C B 1$ in peripheral lymphocytes compared with females, approximately 1.3 -fold, using glyceraldehyde-3P dehydrogenase $(G A P D H)$ as an endogenous control gene for normalization (Chandler et al., 2007). However, another study concluded that beta- 2 microglobulin $(\beta-2 M)$ is a more stably expressed endogenous control gene and should be used for normalization of the expression levels in lymphocytes, rather than GAPDH or beta-actin $($ actin- $\beta)$, and that more than one gene should be used for normalization (Vandesompele et al., 2002).

The gender difference of $A B C B 1$ gene expression in PBMCs using suitable endogenous control genes for normalization is crucial and should be investigated. In addition, limited data of $A B C B 1$ expression in PBMCs is available in the Thai population. Therefore, the present study aimed to determine the expression levels of the $A B C B 1$ gene in PBMCs and to compare them between males and females in healthy Thai individuals, using one or more endogenous control genes for normalization. 


\section{MATERIAL AND METHODS}

\section{Subjects}

Fifty-six (30 females, 26 males) healthy Thai individuals were enrolled in the study. The study was approved by the Institutional Review Boards at Naresuan University, Phitsanulok, Thailand. Individual written consent was obtained from all subjects.

\section{Specimen collection and preparation}

Peripheral blood mononuclear cells were collected at designated study times in a CPT ${ }^{\circledR}$ Cell Preparation Tube. PBMCs were isolated by centrifugation at $1700 \mathrm{~g}$ for $20 \mathrm{~min}$ at room temperature. Afterward, PBMCs were separated from erythrocytes and granulocytes by the polyester gel in the $\mathrm{CPT}^{\circledR}$ vacutainer at room temperature. Specimens were processed immediately upon collection and "flash frozen" using liquid nitrogen. All samples were stored at $-70^{\circ} \mathrm{C}$ until analysis.

\section{Material and chemicals}

QIAamp RNA Blood Mini Kit was purchased from QIAGEN ${ }^{\circledR}$. Brilliant ${ }^{\circ}$ II SYBR $^{\circledR}$ Green QRT-PCR, AffinityScript ${ }^{\mathrm{TM}}$ Master Mix, 2-Step and Alien ${ }^{\circledR}$ QRT-PCR Inhibitor Alert were obtained from Stratagene ${ }^{\mathbb{}}$. $A B C B 1$ primers for quantitative polymerase chain reaction (QPCR) were obtained from SABioscience ${ }^{\mathrm{TM}}$.

\section{RNA isolation and first-strand cDNA synthesis}

Total RNA was isolated from $800 \mu \mathrm{L}$ PBMCs according to the manufacturer protocol (Qiagen ${ }^{\circledR}$, Valencia, CA, USA). All RNA samples were eluted in a final volume of $50 \mu \mathrm{L}$ RNase-Free water (Qiagen ${ }^{\circledR}$ ). Quantification of total RNA concentrations and the purity of all samples were determined using NanoDrop ${ }^{\circledR}$ ND-1000 UV-Vis Spectrophotometer (NanoDrop ${ }^{\circledR}$ Technologies). Isolated RNA samples were stored at $-70^{\circ} \mathrm{C}$ until analysis.

Reverse transcription was performed with 100 ng total RNA using cDNA synthesis kits (Stratagene ${ }^{\circledR}$, Germany), according to manufacturer instructions. First-strand cDNA was synthesized in a $50-\mu \mathrm{L}$ reaction mixture containing $10 \mu \mathrm{L} c \mathrm{cDA}$ synthesis master mix $(2 \mathrm{X}), 3 \mu \mathrm{L}$ of oligo (dT) primer, and $1 \mu \mathrm{L}$ AffinityScript RT/RNase Block enzyme mixture. The reaction mixture was then incubated at $25^{\circ} \mathrm{C}$ for $5 \mathrm{~min}$ to allow primer annealing, at $42^{\circ} \mathrm{C}$ for $45 \mathrm{~min}$ to allow cDNA synthesis and $95^{\circ} \mathrm{C}$ for $5 \mathrm{~min}$ to terminate reverse transcription. Finally, the reaction tubes were stored at $-20^{\circ} \mathrm{C}$ for long-term storage until analysis.

\section{Real-time quantitative polymerase chain reaction}

Real-time QPCR was carried out with Rotor-Gene ${ }^{\mathrm{TM}} 6000$ (Corbette Life Science ${ }^{\mathrm{TM}}$, Germany). The expression of each target gene including $A B C B 1, G A P D H$, actin- $\beta$, and $\beta-2 M$ in PBMCs was determined. A $10-\mu \mathrm{L}$ reaction volume contained $5 \mu \mathrm{L} 2 \mathrm{X}$ Brilliant II SYBR Green QPCR master mix, $0.4 \mu \mathrm{L} A B C B 1$ specific primers (mix of forward and reverse primers, Sabiosciences $^{\mathrm{TM}}$, USA), or $0.2 \mu \mathrm{L}$ forward and $0.2 \mu \mathrm{L}$ reverse primers (Invitrogen ${ }^{\mathrm{TM}}$, USA) for each 
housekeeping gene (Table 1), $1 \mu \mathrm{L}$ of each cDNA template reaction mixture and 3.6 $\mu \mathrm{L}$ DNase-free water. PCRs were initiated with denaturation at $95^{\circ} \mathrm{C}$ for $10 \mathrm{~min}$, followed by 40 cycles of amplification at $95^{\circ} \mathrm{C}$ for $30 \mathrm{~s}$, annealing at $60^{\circ} \mathrm{C}$ for $60 \mathrm{~s}$, and extension at $72^{\circ} \mathrm{C}$ for $30 \mathrm{~s}$. The PCR cycles were followed by a dissociation curve analysis to confirm the single-PCR product at $65-95^{\circ} \mathrm{C}$ with increasing temperature in steps of $0.5^{\circ} \mathrm{C}$ every $10 \mathrm{~s}$. No-template controls were included for each primer pair of each target gene. Each PCR was performed in triplicate. The completed QPCRs of each specific PCR product were stored at $-20^{\circ} \mathrm{C}$.

Table 1. Primer sequences and amplicon size.

\begin{tabular}{llc}
\hline Gene & Sequence $\left(5^{\prime}-3^{\prime}\right)$ & Amplicon length $(\mathrm{bp})$ \\
\hline actin- $\beta$ & Forward: CTG GAA CGG TGA AGG TGA CA & 140 \\
GAPDH & Reverse: AAG GGA CTT CCT GTA ACA ATG CA & 87 \\
$\beta-2 M$ & Forward: TGC ACC ACC AAC TGC TTA GC & 69 \\
& Reverse: GGC ATG GAC TGT GGT CAT GAG & 69 \\
ABCB1 & Forward: CTC CGT GGC CTT AGC TGT G & 105 \\
\hline
\end{tabular}

$G A P D H=$ glyceraldehyde-3P dehydrogenase; actin- $\beta=$ beta-actin; $\beta-2 M=$ beta- 2 microglobulin; $A B C B 1=$ multidrug resistance protein $1(M D R 1)$.

The data were generated with the Rotor Gene 6000 system (Cybeles $^{\circledR}$, Germany). Cycle threshold $(\mathrm{Ct})$ values were calculated for all samples using the Rotor-Gene 6000 Series Software $1.7\left(\right.$ Cybeles $\left.^{\circledR}\right)$. To ensure reliable normalization, three housekeeping genes including actin- $\beta, G A P D H$, and $\beta-2 M$ were tested.

\section{Evaluation of housekeeping genes}

The expressions of three housekeeping genes including GAPDH, actin- $\beta$, and $\beta-2 M$ were evaluated for stability using the Excel-based BestKeeper ${ }^{\circledR B}$ program (Pfaffl et al., 2004) to determine the most suitable housekeeping genes for normalization of $A B C B 1$ expression level. Inputs were $\mathrm{Ct}$ values measured for individuals for each gene (GAPDH, actin- $\beta, \beta-2 M)$. In addition, we combined more than one gene and calculated the mean $\mathrm{Ct}$ for each combination, thereby getting the following combinations: GAPDH + actin- $\beta, G A P D H+\beta-2 M$, actin $-\beta+$ $\beta-2 M$, and $G A P D H+$ actin $-\beta+\beta-2 M$. These combinations were, then, tested for their stability as endogenous control genes. The stability of the individual housekeeping genes is defined by the highest correlation coefficient $(r)$ when compared to the BestKeeeper ${ }^{\circledR}$ index and a standard deviation (SD) of $<1$.

\section{Data and statistical analysis}

Descriptive statistical analysis was performed for numerical data. Delta-delta $\mathrm{Ct}$ method was used to calculate the $A B C B 1$ expression level relative to no-template control. Housekeeping genes were used for normalization of $A B C B 1$ expression to correct for the amount of total RNA added and the amount of the inhibitor during reverse transcription process. The Student $t$-test was used to compare the means of subject characteristics and levels of $A B C B 1$ gene expression between males and females. A P value $<0.05$ was considered to be statistically significant. 


\section{RESULTS}

\section{Subject characteristics}

The subject characteristics are summarized in Table 2. Fifty-six healthy Thai individuals were enrolled, including 30 females and 26 males. The mean age in the female and male groups was similar $(\mathrm{P}>0.05)$. Females had lower total body weight, height, blood pressure, and serum creatinine compared to male subjects $(\mathrm{P}=0.000)$. However, these parameters in both groups were in the normal range. In addition, white blood cell and lymphocyte counts were similar in female and male subjects.

\begin{tabular}{|c|c|c|c|}
\hline Characteristic & Female $(\mathrm{N}=30)$ & Male $(\mathrm{N}=26)$ & Significance level \\
\hline Age (years) & $22.0 \pm 1.1$ & $21.6 \pm 1.3$ & $\mathrm{P}>0.05$ \\
\hline Total body weight $(\mathrm{kg})$ & $48.9 \pm 6.7$ & $66.1 \pm 7.7$ & $\mathrm{P}=0.000$ \\
\hline Height $(\mathrm{cm})$ & $158.5 \pm 4.9$ & $171.7 \pm 6.3$ & $\mathrm{P}=0.000$ \\
\hline Systolic blood pressure $(\mathrm{mmHg})$ & $112.3 \pm 9.7$ & $127.4 \pm 8.2$ & $\mathrm{P}=0.000$ \\
\hline Diastolic blood pressure (mmHg) & $71.4 \pm 7.9$ & $80.6 \pm 8.1$ & $\mathrm{P}=0.000$ \\
\hline Glucose $(\mathrm{mg} / \mathrm{dL})$ & $91.2 \pm 6.4$ & $92.8 \pm 5.0$ & $\mathrm{P}>0.05$ \\
\hline Serum creatinine $(\mathrm{mg} / \mathrm{dL})$ & $0.7 \pm 0.1$ & $1.0 \pm 0.1$ & $P=0.000$ \\
\hline White blood cells $\left(/ \mathrm{mm}^{3}\right)$ & $6663 \pm 1649$ & $6946 \pm 1531$ & $P>0.05$ \\
\hline Lymphocytes $\left(/ \mathrm{mm}^{3}\right)$ & $2490 \pm 631$ & $2697 \pm 712$ & $\mathrm{P}>0.05$ \\
\hline
\end{tabular}

\section{Evaluation of housekeeping gene stability}

We evaluated 3 housekeeping genes for stability including GAPDH, actin- $\beta$ and $\beta-2 M$ using the Bestkeeper ${ }^{\circledR}$ program. Table 3 shows the results from Bestkeeper ${ }^{\circledR}$. When considering a housekeeping gene, actin- $\beta(\mathrm{r}=0.91, \mathrm{SD}=0.69)$ is the most stable gene according to the lowest percent coefficient of variation $(\% \mathrm{CV})$ and $\mathrm{SD}$ and the highest correlation coefficient compared to $\beta-2 M(\mathrm{r}=0.56, \mathrm{SD}=0.69)$ and $G A P D H(\mathrm{r}=0.85, \mathrm{SD}=1.17)$. The levels of GAPDH expression in PBMCs correlated very well with those of actin- $\beta(\mathrm{r}=0.74, \mathrm{P}=0.001)$ but not with those of $\beta-2 M(\mathrm{r}=0.10, \mathrm{P}=0.460)$. However, the level of actin- $\beta$ expression correlated with those of $\beta-2 M(\mathrm{r}=0.36, \mathrm{P}=0.010)$. When considering more than one housekeeping gene, the mean $\mathrm{Ct}$ of two or three housekeeping genes was input in BestKeeper ${ }^{\circledR}$, better correlation coefficients were observed ranging from 0.90 to1.00, with SD ranging from 0.60 to 0.88 and $\% \mathrm{CV}$ ranging from 2.98 to 4.25 .

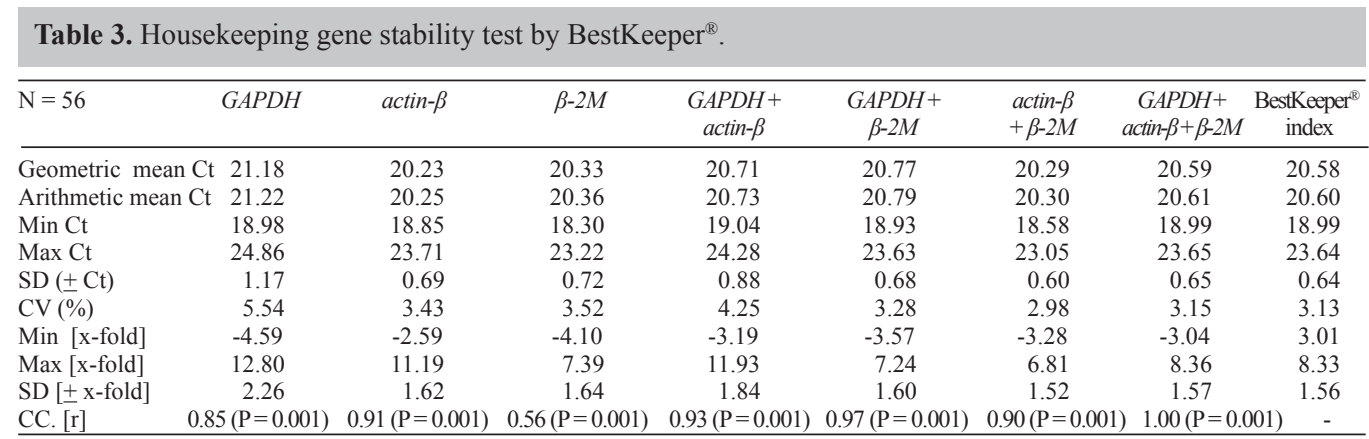

$\mathrm{Ct}=$ cycle threshold; $\mathrm{Min}=$ minimum; $\mathrm{Max}=$ Maximum; $\mathrm{SD}=$ standard deviation; $\mathrm{CV}=$ coefficient of variation; $\mathrm{CC}=$ correlation coefficient. For other abbreviations, see legend to Table 1. 


\section{Gender difference of $A B C B 1$ gene expression levels}

According to the result from Bestkeeper ${ }^{\circledR}, G A P D H$ alone was not suitable for an endogenous control for the determination of $A B C B 1$ expression in PBMCs, and it was, therefore, not used for the normalization of $A B C B 1$ expression levels in PBMCs in this report.

The $A B C B 1$ expression levels in PBMCs in our population showed high inter-individuals variability especially in females $(\% \mathrm{CV}=46.92-126.89)$ compared with males $(\% \mathrm{CV}=$ 48.92-97.83) depending on the endogenous control used. Males had higher levels of $A B C B 1$ expression than females (ranging from 1.5- to 2.5 -fold) but the difference was not statistically significant (Table 4).

\begin{tabular}{|c|c|c|c|c|c|c|}
\hline Fold & actin- $\beta$ & $\beta-2 M$ & $G A P D H+$ actin $-\beta$ & $G A P D H+\beta-2 M$ & $\operatorname{actin}-\beta+\beta-2 M$ & $G A P D H+$ actin $-\beta+\beta-2 M$ \\
\hline \multicolumn{7}{|l|}{ Overall } \\
\hline Mean & -14.95 & -53.94 & -13.48 & -23.50 & -26.88 & -19.78 \\
\hline SD & 12.94 & 75.45 & 6.97 & 15.77 & 29.02 & 14.19 \\
\hline $\mathrm{CV}$ & -86.57 & -139.87 & -51.70 & -67.08 & -107.93 & -71.71 \\
\hline \multicolumn{7}{|c|}{ Female $(\mathrm{N}=30)$} \\
\hline Mean & -18.99 & -75.09 & -15.88 & -28.99 & -35.97 & -24.79 \\
\hline SD & 14.75 & 95.28 & 7.45 & 18.37 & 35.03 & 16.48 \\
\hline $\mathrm{CV}$ & -77.67 & -126.89 & -46.92 & -63.38 & -97.39 & -66.46 \\
\hline \multicolumn{7}{|c|}{ Male $(\mathrm{N}=26)$} \\
\hline Mean & -10.30 & -29.54 & -10.70 & -17.17 & -16.40 & -14.00 \\
\hline SD & 8.61 & 28.89 & 5.23 & 8.81 & 14.68 & 7.92 \\
\hline $\mathrm{CV}$ & -83.67 & -97.83 & -48.92 & -51.29 & -89.51 & -56.59 \\
\hline Ratio M/F & 1.84 & 2.54 & 1.48 & 1.69 & 2.19 & 1.77 \\
\hline
\end{tabular}

$\mathrm{SD}=$ standard deviation; $\mathrm{CV}=$ coefficient of variation .

\section{DISCUSSION}

\section{Evaluation of housekeeping gene stability}

Endogenous reference genes or housekeeping genes are widely used to normalize the mRNA level in relative quantitation to provide an accurate comparison of gene expression between different samples. Traditional endogenous reference genes such as GAPDH, actin- $\beta$ and $\beta-2 M$ have been used for normalization in gene expression analysis for decades. However, the gene expression study may not have proper validation of the housekeeping genes. Recently, the study by Vandesompele et al. (2002) evaluated 10 housekeeping genes from various human tissues. In lymphocytes, it was shown that $\beta-2 M$ was more stable than GAPDH or actin- $\beta$. In contrast, our study showed that when considering single-gene normalization, actin- $\beta$ is the most stable gene for use, compared with $\beta-2 M$ and GAPDH. This may be due to lower numbers of leukocytes in samples in the previous study. However, similar to the findings of Vandesompele et al. (2002), our results suggest that more than one endogenous control genes should be used for normalization of gene expression levels. In the present study, when we used $G A P D H$, which had the least stability compared to the others, the $A B C B 1$ expression levels between males and females were almost equal.

On the other hand, normalization using $\beta-2 M$ or actin- $\beta$ showed higher differences of $A B C B 1$ expression levels between males and females. Therefore, gene expression pro- 
files need to be carefully interpreted beforehand, taking into account the endogenous control genes used.

\section{Gender difference of $A B C B 1$ gene expression levels}

P-gp is expressed in various tissues, including PBMCs and especially CD56+ natural killer cells, CD8+ T cells and CD4+ helper T cells, which are the sites of action for numerous immunosuppressive drugs (Hitzl et al., 2001; Fellay et al., 2002; Oselin et al., 2003). P-gp has been reported to participate in the transport of cytokines, including interleukin-2 (IL-2), IL-4 and interferon-gamma (IFN- $\gamma$ ) (Oselin et al., 2003). These findings indicate that P-gp may play a role in specific immunological functions.

In this study, significant inter-subject variability was noted in $A B C B 1$ expression levels in PBMCs with a \%CV of 40-107. These are in agreement with the findings from previous studies of P-gp expression levels in liver (Schuetz et al., 1995; Paine et al., 2005). When gene expression levels were compared in males versus females, we found that females have lower $A B C B 1$ expression levels in PBMCs with a male to female $A B C B 1$ expression ratio of 1.48- to 2.54-folds, according to the housekeeping gene used for normalization. Even though these gender-related differences were not statistically significant $(\mathrm{P}>0.05)$, we cannot discard this possibility, which may account for the variability of drug (substrate) disposition between females and males.

The difference in P-gp expression levels between males and females may lead to differences in drug response and toxicity. A review by Singh et al. (2005) suggests that females are more susceptible to drug toxicity (myelosuppression, nausea, vomiting, and stomatitis) from chemotherapy regimens, including cyclophosphamide, vincristine, doxorubicin, etoposide, and platins, relative to males. These may be explained by differences in intracellular levels depending on P-gp expression, since vincristine, doxorubicin and etoposide are substrates of P-gp. Another study reported that females have lower hepatic P-gp expression compared to males (Schuetz et al., 1995). Therefore, females may have higher bioavailability with prolonged drug half-life and reduced drug elimination relative to males. Subsequently, females may have a greater risk of myelosuppression and gastrointestinal toxicity. In contrast, females may show a better response to the drug than males due to prolonged drug exposure.

A study reported that the expression of $A B C B 1$ gene in lymphocytes extracted from HIV-positive patients was significantly greater in males relative to females, using $G A P D H$ as an endogenous control with a male to female expression ratio of 1.34-fold (Chandler et al., 2007). However, the present findings suggest that $G A P D H$ should not be used as a singleendogenous control for normalization of $A B C B 1$ gene expression in PBMCs. Gender-related $A B C B 1$ expression may in part explain the higher exposure to saquinavir (Ribera et al., 2004) and to indinavir (Brendel et al., 2005) found in females compared with males. It should be noted that the pharmacokinetics of P-gp substrates is influenced by other transporters and metabolic enzymes, for example, cytochrome P450 enzymes and CXCR4 chemokine receptors (Owen et al., 2004; Paine et al., 2005). Even though the expression of the $A B C B 1$ gene in PBMCs was similar to finding of another study investigating gene expression level in liver (Schuetz et al., 1995), we may not be able to conclude that PBMCs is a valid surrogate marker in determining the expression levels of $A B C B 1$ gene in other tissues. In addition, a recent study found that there is no correlation of $A B C B 1$ expression in intestine and liver with the gene expression levels in PBMCs (Albermann et al., 2005). 
In contrast, a recent study showed that females required a higher dose of cyclosporine compared to males in order to prevent acute rejection in rat with kidney transplantation (Muller et al., 2008). These contrary results suggest that P-gp may have an influence on drug exposure differently in regard to drug substrates and tissues. In summary, the present study provides evidence that $A B C B 1$ expression in PBMCs is greater in males compared to females, using proper endogenous control genes for normalization. Consequently, these findings may in part explain the gender-related drug responses and drug toxicities of P-gp substrates.

\section{ACKNOWLEDGMENTS} (NRTC).

Research supported by the Office of the National Research Council of Thailand

\section{REFERENCES}

Albermann N, Schmitz-Winnenthal FH, Z'graggen K, Volk C, et al. (2005). Expression of the drug transporters MDR1/ $\mathrm{ABCB} 1, \mathrm{MRP} 1 / \mathrm{ABCC} 1, \mathrm{MRP} 2 / \mathrm{ABCC} 2, \mathrm{BCRP} / \mathrm{ABCG} 2$, and PXR in peripheral blood mononuclear cells and their relationship with the expression in intestine and liver. Biochem. Pharmacol. 70: 949-958.

Brendel K, Legrand M, Taburet AM, Baron G, et al. (2005). Population pharmacokinetic analysis of indinavir in HIVinfected patient treated with a stable antiretroviral therapy. Fundam. Clin. Pharmacol. 19: 373-383.

Chandler B, Detsika M, Khoo SH, Williams J, et al. (2007). Factors impacting the expression of membrane-bound proteins in lymphocytes from HIV-positive subjects. J. Antimicrob. Chemother. 60: 685-689.

Fellay J, Marzolini C, Meaden ER, Back DJ, et al. (2002). Response to antiretroviral treatment in HIV-1-infected individuals with allelic variants of the multidrug resistance transporter 1: a pharmacogenetics study. Lancet 359: 30-36.

Hitzl M, Drescher S, van der Kuip H, Schaffeler E, et al. (2001). The C3435T mutation in the human MDR1 gene is associated with altered efflux of the P-glycoprotein substrate rhodamine 123 from CD56+ natural killer cells. Pharmacogenetics 11: 293-298.

Hoffmann U and Kroemer HK (2004). The ABC transporters MDR1 and MRP2: multiple functions in disposition of xenobiotics and drug resistance. Drug Metab. Rev. 36: 669-701.

MacLean C, Moenning U, Reichel A and Fricker G (2008). Closing the gaps: a full scan of the intestinal expression of P-glycoprotein, breast cancer resistance protein, and multidrug resistance-associated protein 2 in male and female rats. Drug Metab. Dispos. 36: 1249-1254.

Muller V, Szabo AJ, Erdely A, Tain YL, et al. (2008). Sex differences in response to cyclosporine immunosuppression in experimental kidney transplantation. Clin. Exp. Pharmacol. Physiol. 35: 574-579.

Oselin K, Nowakowski-Gashaw I, Mrozikiewicz PM, Wolbergs D, et al. (2003). Quantitative determination of MDR1 mRNA expression in peripheral blood lymphocytes: a possible role of genetic polymorphisms in the MDR1 gene. Eur. J. Clin. Invest. 33: 261-267.

Owen A, Chandler B, Bray PG, Ward SA, et al. (2004). Functional correlation of P-glycoprotein expression and genotype with expression of the human immunodeficiency virus type 1 coreceptor CXCR4. J. Virol. 78: 12022-12029.

Paine MF, Ludington SS, Chen ML, Stewart PW, et al. (2005). Do men and women differ in proximal small intestinal CYP3A or P-glycoprotein expression? Drug Metab. Dispos. 33: 426-433.

Pfaffl MW, Tichopad A, Prgomet C and Neuvians TP (2004). Determination of stable housekeeping genes, differentially regulated target genes and sample integrity: BestKeeper-Excel-based tool using pair-wise correlations. Biotechnol. Lett. 26: 509-515.

Potter JM, McWhinney BC, Sampson L and Hickman PE (2004). Area-under-the-curve monitoring of prednisolone for dose optimization in a stable renal transplant population. Ther. Drug Monit. 26: 408-414.

Ribera E, Lopez RM, Diaz M, Pou L, et al. (2004). Steady-state pharmacokinetics of a double-boosting regimen of saquinavir soft gel plus lopinavir plus minidose ritonavir in human immunodeficiency virus-infected adults. Antimicrob. Agents Chemother. 48: 4256-4262.

Roninson IB, Chin JE, Choi KG, Gros P, et al. (1986). Isolation of human mdr DNA sequences amplified in multidrugresistant KB carcinoma cells. Proc. Natl. Acad. Sci. U. S. A. 83: 4538-4542. 
Schinkel AH and Jonker JW (2003). Mammalian drug efflux transporters of the ATP binding cassette (ABC) family: an overview. Adv. Drug Deliv. Rev. 55: 3-29.

Schuetz EG, Furuya KN and Schuetz JD (1995). Interindividual variation in expression of P-glycoprotein in normal human liver and secondary hepatic neoplasms. J. Pharmacol. Exp. Ther. 275: 1011-1018.

Singh S, Parulekar W, Murray N, Feld R, et al. (2005). Influence of sex on toxicity and treatment outcome in small-cell lung cancer. J. Clin. Oncol. 23: 850-856.

Vandesompele J, De Preter K, Pattyn F, Poppe B, et al. (2002). Accurate normalization of real-time quantitative RT-PCR data by geometric averaging of multiple internal control genes. Genome Biol. 3: RESEARCH0034. 